\title{
Enzyme-linked Immunosorbent Assay for Detection and Quantification of Cryptococcus neoformans Antigen
}

\author{
Ma.Teresa Illnait, Juan C Vilaseca, Carlos M Fernández, Gerardo F Martínez ${ }^{+}$
}

\author{
Laboratorio de Micología, Instituto Pedro Kourí, Apto. 601, Marianao 13, Havana, Cuba
}

An enzyme-linked immunosorbent assay was standardized for the detection of cryptococcal antigen in serum and cerebrospinal fluid. The system was evaluated in clinical samples from patients infected by human immunodeficiency virus with and without previous cryptococcosis diagnosis. The evaluated system is highly sensitive and specific, and when it was compared with latex agglutination there were not significant differences. A standard curve with purified Cryptococcus neoformans antigen was settled down for the antigen quantification in positive samples.

Key words: cryptococcal antigen - antigen quantification - antigen detection - enzyme-linked immunosorbent assay-ELISA

In the past, various factors have resulted in an increase in the number of immunocompromised patients. None of these factors, however, had the same degree of impact as the dramatic worldwide epidemic of acquired immunodeficiency syndrome (Aids) (Duppont et al. 1992). Cryptococcus neoformans, encapsulated yeast, is responsible for disseminated meningoencephalitis mostly in patients with cellular immune defects. The yeast exists in two varieties, $C$. neoformans var. neoformans which corresponds to serotypes $A$ and $D$, and $C$. neoformans var. gattii which corresponds to serotypes $B$ and $C$ (Dromer et al. 1993, 1994) .

Cryptococcosis is currently the most common life threatening mycosis found in patients with Aids. Extrapulmonary involvement is most frequently observed, mainly in the central nervous system (Duppont et al. 1992, Buckley et al. 1992). The prognosis of this infection is poor unless it is diagnosed and treated promptly (Buckley et al. 1992).

Serological tests can provide the most rapid tools for establishing a diagnosis of this fungal infection; they allow that a rapid therapy can be initiated (Repentigni 1989). Antigen detection test represents the most immediate way to improve methods for cryptococcosis serodiagnosis. Significant progress has been made in this area over recent years (Diamond \& Bennett 1974, Gordon \& Vedder 1996). Latex agglutination (LA) has been

\footnotetext{
${ }^{+}$Corresponding author. Fax: 537-246051. E-mail: gerardo@ipk.sld.cu

Received 16 December 1999

Accepted 5 September 2000
}

evaluated extensively and it may be used to monitor the disease course and response to treatment by serial determination of antigen titers (Dupont et al. 1992, Temstet et al. 1992). Nowadays most clinical laboratories use LA assays despite occasional reports of false-negative results (Currie et al. 1993).

Enzyme-linked immunosorbent assays (ELISA) for detection of cryptococcal antigen has been described (Casadevall et al. 1992, Mukjerjee $\&$ Casadevall 1995). ELISA has several potential advantages over LA, including clear discrimination of positive from negative results (cut off), ability to provide quantitative information without endtiter dilution and higher sensitivity (Dupont et al. 1992). We now report a direct ELISA for detection and quantification of $C$. neoformans capsular polysaccharide (CPS).

\section{MATERIALS AND METHODS}

ELISA standardization - It was carried out according to the methodology described by Voller et al. (1979) for direct ELISA. Briefly, polyestirene microtitration plates (NUNC, USA) were coated with $100 \mu \mathrm{l} /$ well of monospecific rabbit polyclonal IgG against cryptococcal antigen (Illnait et al. 1998) at optimal concentration in coating buffer $\left(\mathrm{NaCO}_{3} / \mathrm{NaHCO}_{3}\right) \mathrm{pH}$ 9.0. The rest of the plastic binding sites were saturated with a solution of $1 \%$ of bovine seroalbumin (BSA V fraction) in the same buffer ( $150 \mu \mathrm{l} /$ well).

A pool of five sera from human immunodeficiency virus infected patients without any evidence of cryptococcosis was used as negative control. On the other hand, an Aids patient serum with clinical and laboratory diagnosis of cryptococcosis was used as positive control. A total of 100 negative samples (50 sera and 50 cerebrospinal fluids) were 
studied for cut off determination by means of two times the standard deviation. All samples and controls were stored at $-20^{\circ} \mathrm{C}$, and they were diluted in phosphate buffer solution (PBS) containing $0.5 \%$ Tween 20 (T20).

Another lot of antibodies against $C$. neoformans obtained in the same way was conjugated using peryodate method (Mukjerjee \& Casadevall 1995) with type VI horseradish peroxidase (P8375, SIGMA, USA). A hundred $\mu 1 /$ well of $1 / 2000,1 /$ $4000,1 / 8000$ and $1 / 12000$ from each dilutions of this conjugated in PBS-T20 containing 5\% fetal bovine serum were applied. The substrate (orthophenylene diamine, Merck, Darmstadt, Germany): $0.4 \mathrm{mg} / \mathrm{ml}, 0.1 \mathrm{~mol} / \mathrm{l}$ citrate phosphate buffer $\mathrm{pH}$ $5.5,0.003 \% \mathrm{H}_{2} \mathrm{O}_{2}$ ) was added and the reaction was stopped $10 \mathrm{~min}$ later by the addition of $50 \mu \mathrm{l} /$ well $12.5 \% \mathrm{H}_{2} \mathrm{SO}_{4}$. During the process each step was followed by $1 \mathrm{~h}$ incubation at $37^{\circ} \mathrm{C}$ and three washes with PBS-T20. Correlation using different incubation conditions $\left(2 \mathrm{~h}\right.$ at $37^{\circ} \mathrm{C}$ and overnight at room temperature) was considered for coating.

System evaluation - A total of 142 samples were used: 45 sera and 43 cerebrospinal fluids from patients without any evidence of cryptococcosis; 30 sera and 24 cerebrospinal fluids from patients with cryptococcosis confirmed by culture. Latex particles $(0.8 \mu \mathrm{m}, 10 \%$ solution, Rhone Poulec) sensibilized with IgG anti $C$. neoformans which had similar sensitivity to Meridian Diagnostic Inc. System was used (Alvarez et al. 1992). ELISA dependence degree with latex, like reference technique, using Fisher test of the exact probability was estimated. System specificity, efficacy and repeatability were considered as quality indexes (Porstman \& Keessing 1992). Absolute sensibility in term of minimum detectable quantity of purified polysaccharide glucuronoxylomannan (GXM) was also calculated using value of blank average plus 2.8 times blank standard deviation (Porstman \& Keessing 1992).
Antigen quantification in positive samples was carried out. Appropriate double dilutions using PBS-T20 were done and antigen concentration was determined using a standard curve of purified GXM (Nakane \& Kawaoi 1974). A computer assisted multiplicative (power) regression plotting (model $\mathrm{y}=\mathrm{ax}^{\mathrm{b}}$ ) for the GXM quantification (Statgraphics, ver 4.0, Statistical Graphics Co., USA) was used.

\section{RESULTS}

We selected as optimal IgG working dilution $20 \mu \mathrm{g} / \mathrm{ml}$. No significant differences were found between different BSA percentages, so we preferred $1 \%$ of BSA for blocking. Samples and conjugate dilutions were $1 / 32$ and $1 / 12000$, respectively. The cut off value was 0.1 for sera and 0.04 for CSF.

The correlation between two different incubation conditions (overnight at room temperature and $2 \mathrm{~h}$ at $37^{\circ} \mathrm{C}$ ) was $95 \%$. The sensibility was $100 \%$ for both types of samples. Specificity was $97.9 \%$ and $95.5 \%$ and efficacy 99 and $97.1 \%$ for sera and cerebrospinal fluid respectively in each case. Non significant differences between ELISA and LA were observed $(\mathrm{p}<0.05)$.

Using a purified GXM from $C$. neoformans var. neoformans serotipe $A$ a standard curve was developed (Fig. 1). The absolute sensibility of the system and the antigen concentration in positive samples was determined $(0.19 \mathrm{ng} / \mathrm{ml})$.

Fig. 2 shows the sample behavior evaluated by LA and ELISA and correspondence among concentration determined by ELISA and titers obtained by LA. We found that a range below from $190 \mathrm{pg} /$ $\mathrm{ml}$ to $60 \mathrm{ng} / \mathrm{ml}$ is useful to estimate the GXM concentration by a computer assisted multiplicative (power) regression plotting (model $\mathrm{y}=\mathrm{ax}^{\mathrm{b}}$ ). This analysis could be transformed in simple linear regression applying 10-based logarithms to GXM concentration (x) and optical density (y).

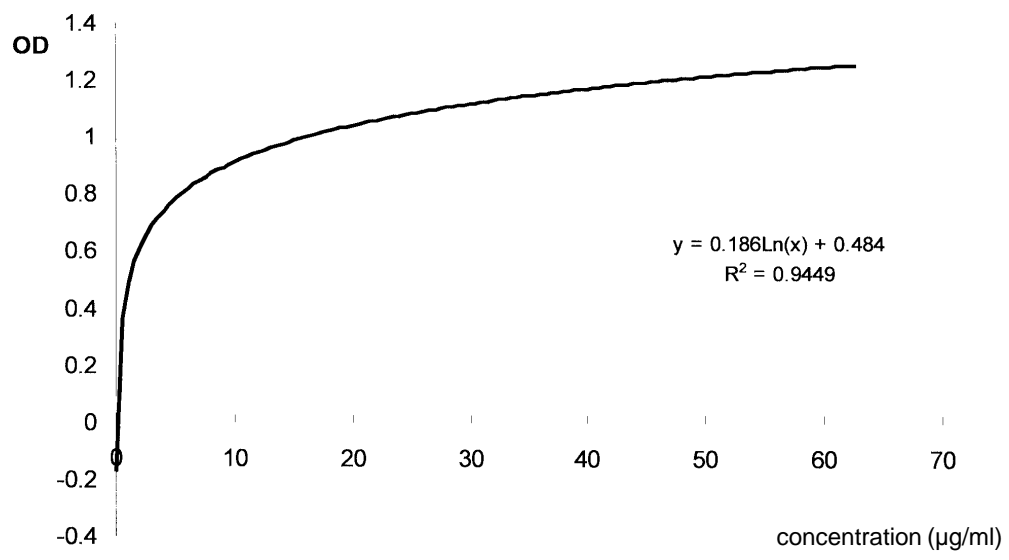

Fig. 1: standard curve of purified polysaccharide 

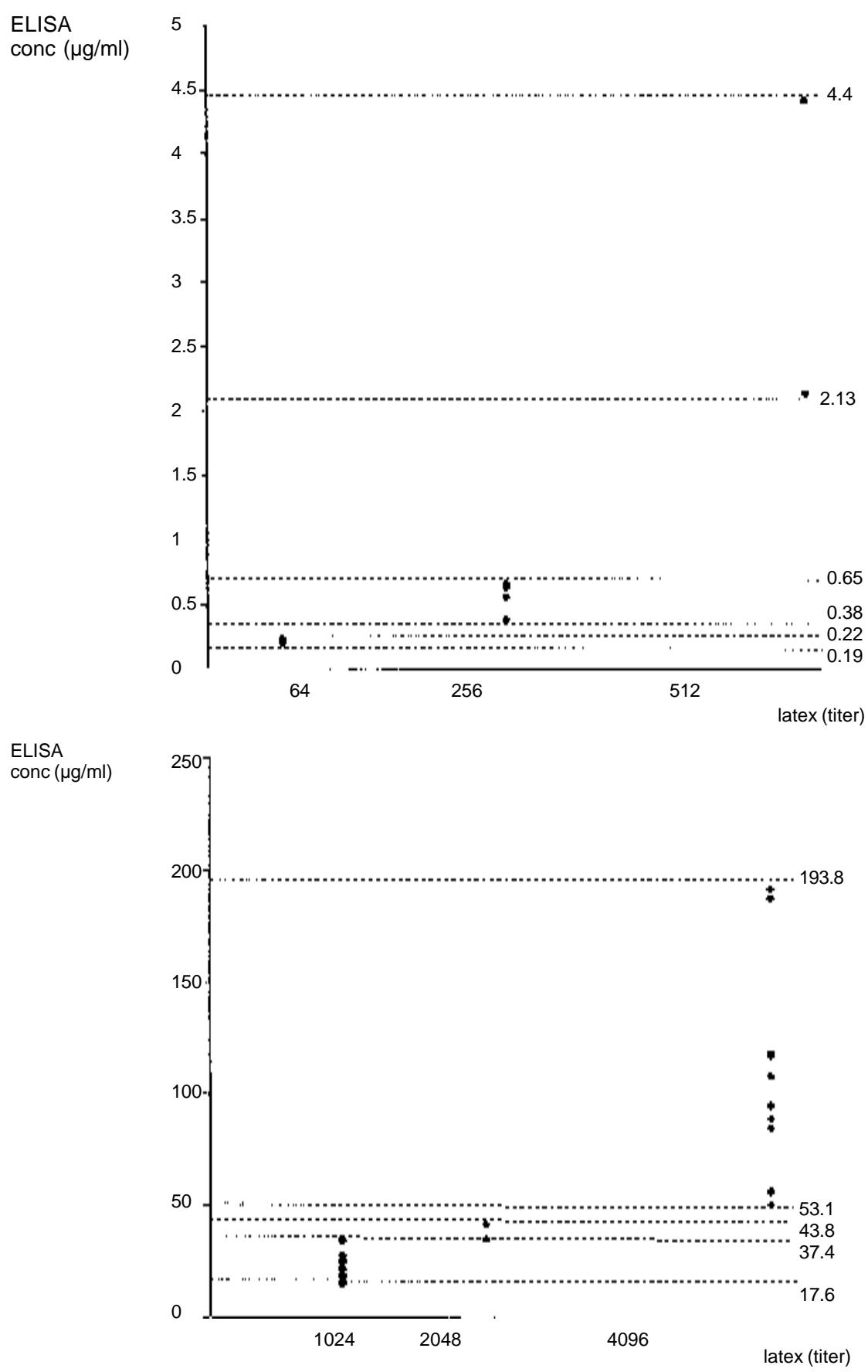

Fig. 2: correspondence among concentration determined by enzym-linked immunosorbent assay and titers obtained by latex.

\section{DISCUSSION}

Correlation obtained between incubation conditions shows the possibility of shortening it if is necessary without affecting the results. One percent BSA was satisfactory for blocking. These results are similar to other reports (Scott et al. 1980, Gade et al. 1991). It is known that casein, as block- ing substance, may diminish process cost and the results do not change, even improving in some cases (Vogt et al. 1987). However, in our case their use was not satisfactory since high background values were obtained (data not shown).

Sample dilution of $1 / 32$ was chosen in spite of OD rate between positive and negative samples. It 
does not show the best result, but the values of optical density of the control samples were optimal and this relation stayed above. Dilutions below 1/32 favored the background development, which was directly proportional to the sample concentration. Conjugate activity was demonstrated by its capacity to detect antigen in low dilution. Its quality as reagent is evidenced because it kept the biological activity at high dilution (1/12000).

The quality parameters analyzed (sensibility, specificity and efficacy) are considered acceptable for immunoenzymatic tests (Porstman \& Keessing 1992).

LA has been satisfactorily used in our laboratory. However, false positive results with the presence of rheumatoid factor have been obtained sometimes. This fact and subjective interpretation disadvantages have been recognized in similar diagnostic systems.

Uwe et al. (1993) evaluated the Premier Enzyme Immunoassay (Meridian Diagnostic Inc.) with the purpose to compare it with LA test for the detection of cryptococcal antigen in serum. ELISA titers were determined using the formula $\mathrm{A}_{450}$ / $\mathrm{A}_{630} \mathrm{X}$ dilution of control factor, whereas the control factor for each lot was determined using the formula 12/average adsorbance of positive control. We have established the correlation between the LA titer and the antigen concentration by ELISA. The possibility of knowing the exact antigen concentration in samples could help to physicians to determine the disease evolution as well as treatment efficacy (Diamond \& Bennett 1974, Gordon $\&$ Vedder 1996). In the consulted literature we did not find antecedents on similar systems that permit the antigen quantification in pathological samples using a standard curve. The used of serotype $A$ of $C$. neoformans in the standard curve has been determined by its worldwide incidence so in patients with and without Aids (Fernández et al. 1990, 1991, Stuart 1991, Neil \& Ampel 1996).

The development of this technique allows to the Mycology Laboratory face quick and reliable the cryptococcosis diagnosis. Both, clinical suspicion and illness diagnosis in initial stages avoid severe complications and death. It also permits the clinical pursuit of the patients and the evaluation of the treatment efficacy upon knowing the exact antigen concentration in samples.

\section{REFERENCES}

Alvarez L, Martinez G, Fernández C, Llop A 1992. Diagnóstico de criptococosis. Comparación de dos sistemas latex para la detección de antígeno. Rev Cub Med Trop 44: 29-32.

Buckley HR, Richardson MD, Evans EGV, Wheat LJ 1992. Immunodiagnosis of invasive fungal infection.
J Med Vet Mycol 30(Suppl. 1): 249-260.

Casadevall A, Mukherjee J, Scharff D 1992. Monoclonal antibody based ELISAs for Cryptococcus polysaccharide. J Immunol Methods 154: 27-35.

Currie BP, Freundlich LF, Soto MA, Casadevall A 1993. False negative cerebrospinal fluid cryptococcal latex agglutination test for patients with culture-positive cryptococcal meningitis. J Clin Microbiol 3: 2519-2522.

Diamond RD, Bennet JE 1974. Prognostic factors in cryptococcal meningitis. A study in 111 cases. Ann Intern Med 80: 176-181.

Dromer F, Gueho E, Ronin O, Dupont B 1993. Serotyping of Cryptococcus neoformans by using a monoclonal antibodies specific for capsular polysaccharide. J Clin Microbiol 31: 359-363.

Dromer F, Varma A, Ronin O, Mathoulin S, Dupont B 1994. Molecular typing of Cryptococcus neoformans serotype $D$ clinical isolates. J Clin Microbiol 32: 2364-2371.

Dupont B, Graybill JR, Armstrong D, Laroche R, Touzé JE, Wheat LT 1992. Fungal infections in AIDS patients. J Med Vet Mycol 30 (Suppl. 1): 19-28.

Fernández C, Martínez G, Alvarez LP, Rodríguez R, Alvarez C 1990. Cryptococcus neoformans var. neoformans isolated in Havana City. Mem Inst Oswaldo Cruz 85: 245.

Fernández C, Martínez G, Menéndez de San Pedro J, Oramas B 1991. Identificación de las variedades de Cryptococcus neoformans mediante utilización de medios de cultivo. Rev Cub Med Trop 43: 100-102.

Gade W, Hinnefeld SW, Babcock JS, Gillan P 1991. Comparison of the premier cryptococcal antigen. Enzyme immunoassay and latex agglutination assay for cryptococcal antigen. J Clin Microbiol 29: 1616-1619.

Gordon MA, Vedder DK 1996. Serologic test in diagnosis and prognosis of cryptococcosis. JAMA 197: 961-965.

1llnait MT, Martínez G, Fernández C 1998. Obtención de IgG específica anti Cryptococcus neoformans. Rev Cub Med Trop 50: 27-30.

Mukjerjee S, Casadevall A 1995. Sensitivy of sandwich enzyme-linked immunosorbent assay for Cryptococcus neoformans polysaccharide antigen is dependent on the isotype of the capture and detection antibodies. J Clin Microbiol 33: 765-768.

Nakane PK, Kawaoi A 1974. Peroxidase-labeled antibody. A new method of conjugation. Histochem Cytochem 22: 1084-1091.

Neil M, Ampel MD 1996. Emergin disease and fungal pathogens associated with HIV infection. Emergin Infect Dis 2: 109-116.

Porstman T, Keessing ST 1992. Enzyme immunoassay techniques. An overview. J Immunol Methods 150: 5-21.

Repentigni L 1989. Serological techniques for diagnosis of fungal infections. Eur J Clin Microbiol Infect Dis 8: 362-375.

Scott EN, Muchmore HG, Felton FG 1980. Comparison of enzyme immunoassay and latex agglutination for detection of Cryptococcus neoformans anti- 
gen. Am J Clin Pathol 6: 790-793.

Stuart M 1991. The ecology of Cryptococcus neoformans and the epidemiology of cryptococcosis. Rev Infect Dis 13 (Nov-Dec): 1163-1169.

Temstet A, Roux P Poirot JL, Ronin O, Dromer F 1992. Evaluation of monoclonal antibody based latex agglutination test for diagnosis of criptococcosis. Comparison with two tests using polyclonal antibodies. J Clin Microbiol 30: 2544-2450.

Uwe KF, Nishimura SL, Li NC, Sugai K, Yajko DM, Hadley WK 1993. Evaluation of an enzyme immu- noassay for detection of cryptococcal capsular polysaccharide antigen in serum and cerebrospinal fluid. J Clin Microbiol 31: 97-101.

Vogt RF, Philips DL, Henderson O, Whitfield W, Spierto FW 1987. Quantitative differences among various proteins as blocking agents for ELISA microtiter plates. J Immunol Methods 101: 43-50.

Voller A, Bidwell DE, Bartlett A 1979. The ELISA: a Guide with Abstracts of Microplate Application. Dynatech Europe, Borough House, Rue du Pre, Guersney, Great Britain, p. 42-50. 